\title{
RESOURCE ATTRIBUTES THAT CONTRIBUTE TO NONRESIDENT DIVER SATISFACTION IN THE FLORIDA KEYS, USA
}

\author{
SHONA PATERSON, ${ }^{*}$ SARAH YOUNG, ${ }^{*}$ DAVID K. LOOMIS, $*$ and WILLIAM OBENOUR $\dagger$ \\ *Institute for Coastal Science and Policy, East Carolina University, Greenville, NC, USA \\ $\dagger$ Recreation and Leisure Studies Department, Center for Sustainable Tourism, \\ East Carolina University, Greenville, NC, USA
}

\begin{abstract}
Scuba diving is a popular form of marine-based tourism contributing over $\$ 1$ billion annually to the tourism industry in the Florida Keys. This research explores diver characteristics, how segmentation into meaningful subgroups can be achieved, and how various factors affect satisfaction. Data were collected from nonresident divers and a 10-item index was created based on respondents' satisfaction. Discrepancy was calculated using the same items, and a specialization index was used to subgroup the respondents. Data were analyzed using step-wise regression. Results revealed that discrepancies for individual items contributed to satisfaction, which differed according to specialization level. This suggests that satisfaction is related to both discrepancies between expectations and experiences, and specialization level, providing avenues for strategic marketing and management.
\end{abstract}

Key words: Scuba diving; Satisfaction; Specialization; Florida Keys

\section{Introduction}

Scuba diving is a growing component of international and domestic tourism markets, with divers traveling extensively around the world to experience the marine environment in a variety of ways. The quantification of the economic values associated with diving is difficult due to the fact that both market and nonmarket values must be accounted for since the activity generates value for local businesses, as well as participants (Pendleton \& Rooke, 2006). Nevertheless, it has been estimated that scuba diving contributes over $\$ 1$ billion annually to the economy of Monroe County alone, of which the Florida Keys are a part (Leeworthy \& Ehler, 2010; Leeworthy, Loomis, \& Paterson, 2010; Leeworthy \& Wiley, 2001). This substantial contribution to the economic well-being of the Florida Keys provides a strong incentive to understand the characteristics of visiting divers, in order to tailor experiences to maximize recreational opportunities and satisfaction as well as optimize market strategies.

A wide range of scuba diving experiences is promoted in the Florida Keys, including dives to shallow sea grass beds, reefs, coral gardens, wreck diving, drift diving, and cave and canyon diving, all 
at a variety of depths and levels of difficulty depending on access, tides, currents, and visibility. Understanding visitors' expectations, whether their actual experience meets expectations, and what influences different divers' level of satisfaction are key components of market recognition and provide information that is critical when managing for quality experiences. Subgrouping the diving population by different tourism/recreational/experience requirements allows both resource managers (Dearden, Bennett, \& Rollins, 2006, 2007) and the tourism industry (Dimmock, 2009) to be more targeted in their communications with this recreational audience. If differences do exist between subgroups of divers, then opportunities to improve the recreational experience achieved by tourists while enhancing conservation and economic interests can be examined.

A comprehensive body of literature exists regarding the biological impact of recreational scuba diving on coral reefs (Barker \& Roberts, 2004; Hasler \& Ott, 2008; J. P. Hawkins \& Roberts, 1993; J. P. Hawkins et al., 1999; Rouphael \& Inglis, 1997; Tratalos \& Austin, 2001), contingent valuation methods to estimate revenues generated by the dive industry (Tapsuwan \& Asafu-Adjaye, 2008), potential for diving fees to contribute to management costs (Asafu-Adjaye \& Tapsuwan, 2008; Thur, 2010; Wielgus, Balmford, Lewis, Mora, \& Gerber, 2010), and recreational carrying capacity for scuba divers (Davis \& Tisdell, 1995; Di Franco, Marchini, Baiata, Milazzo, \& Chemello, 2009). However, data on divers' experiences, preferences, and level of satisfaction regarding different dive opportunities are more limited (MacCarthy, O’Neill, \& Williams, 2006; Musa, 2002; Musa, Kadir, \& Lee, 2006; Sorice, Oh, \& Ditton, 2007). The aim of this study is to investigate how physical and biological characteristics associated with diving in the marine environment of the Florida Keys, or resource attributes, contribute to diver satisfaction. Differences in nonresident/tourist diver expectations vs. the experience they obtain are also explored to better understand the levels of satisfaction reported. Understanding satisfaction levels and the drivers behind these levels can assist both resource managers and the tourism industry in being more effective over time. Three main social theories, satisfaction, expectancy/discrepancy, and recreation specialization, will be discussed during this article to provide a conceptual context for the results and discussion.

\section{Literature Review}

\section{Tourism Experience}

One component of Leiper's (1990) framework demonstrates the concept that tourist destinations may have certain services with distinct attractive features that attract tourists. This can easily be applied to the marine destination region and the wide mixture of attractions for the adventure traveler. These include: a) species of wildlife (e.g., whales and sharks); b) scenery above or below the water surface, such as coral reefs and underwater formations; c) active participation involving skill and coordination, such as kayaking and scuba diving; and d) activity-based with short-term adrenalin boost as a spectator or participant (Buckley, 2010). Wildlife and scenery are examples of two destination attributes in the Florida Keys that are "pull" factors (Crompton, 1979), which encourage visitation by scuba divers (Jennings, 2003).

Conceptual models of the tourist experience advocate satisfaction as a key variable influencing destination choices (Ryan, 2002), personal and collective behavior (Bowen \& Clarke, 2009), the travel experience (Cutler \& Carmichael, 2010), and return visitation (Campo-Martínez, Garau-Vadell, \& Martínez-Ruiz, 2010). Each potential marine destination encompasses a mix of attraction and supply attributes that are evaluated by tourists to determine their level of satisfaction with the destination visited (Alegre \& Garau, 2010).

\section{Satisfaction}

Satisfaction is a broad conceptual framework that has been defined in numerous ways throughout the recreation and tourism literature over time. Definitions that are now widely used include the concept of a consumer's fulfillment response, as well as a broad evaluation of an experience or service that is influenced by perceptions of experience quality, service quality, price, and other factors (Beard \& Ragheb, 1980; Chipman \& Helfrich, 1988; J. Lee, Graefe, \& Burns, 2004; Manning, 1999; Ragheb, 1980). In the tourism arena, satisfaction 
has been examined in travel agencies, accommodation, destinations, and tours (Baker \& Crompton, 2000; Bigne, Sanchez, \& Sanchez, 2001; del Bosque \& Martin, 2008; Joppe, Martin, \& Waalen, 2001; Kozak, 2001; C. Lee, Lee, \& Lee, 2005) and has been shown to contribute to repeat visitation, destination loyalty, and increased recommendation (Alexandris, Kouthouris, \& Meligdis, 2006; Oppermann, 2000; Yoon \& Uysal, 2005).

Researchers commonly and routinely use the post hoc satisfaction model consisting of tourists' expectations as the dominate perspective in analyzing tourists' experiences (Mannell \& Iso-Ahola, 1987). Satisfaction can also be understood as the difference between what is expected and what is actually experienced (Burns, Graefe, \& Absher, 2003; Lawler, 1973), and it is this element of the overarching satisfaction concept that is utilized in this study

In terms of scuba diving specifically, tourists' satisfaction has mostly been derived from the dive itself, diver operator services, destination characteristics and the social interaction with other divers (MacCarthy et al., 2006). Divers have been shown to be more inclined to spend their money in areas with intact and rich marine environments (Moscardo, 1999; Pendleton, 1994; Rudd \& Tupper, 2002). Over the last 20 years, many tropical countries have developed substantial dive industries as visitors have become aware of the beauty and ease of diving in tropical environments (Musa, 2002). Researchers have found that divers take into account a variety of resource attributes in their appraisal of satisfaction, such as water clarity, number and quality of underwater formations, and type, volume, and rarity of species (Fitzsimmons, 2008; Musa et al., 2006).

\section{Expectancy/Discrepancy}

Pizam, Neumann, and Reichel (1978) defined tourist satisfaction as the result of comparing tourists' experience at destination visited with their expectations about that destination. Expectancy/ discrepancy theory suggests that satisfaction is a measure of how close a person's desired experiential outcome (expectation) is to that person's perceived reality when or after the activity takes place (Pizam \& Milman, 1993; Porter \& Lawler, 1968; Vroom, 1964). When visitor perceptions of reality meet or exceed expectations, visitors tend to be more satisfied (Manning, 1999).

Expectancy-value theory also states that individuals may have a variety of motives for participating in an activity (Todd, Graefe, \& Mann, 2002). Furthermore, individuals participating in a particular activity may seek totally different outcomes. Therefore, in order for resource managers to fully understand user satisfaction, it is important to include the contextual breadth that expectations and discrepancies offer. It is also important to recognize that the "average user" does not exist (Bryan, 1977; Shafer, 1969). Calculating or otherwise determining average satisfaction of all users is of limited utility since it would describe very few users. Segmenting the larger population of users into meaningful subgroups is, therefore, not only preferred but also necessary. One approach for doing this is recreation specialization.

\section{Recreation Specialization}

Recreation specialization theory was first proposed by Bryan (1977), later refined by Ditton, Loomis, and Choi (1992), and subsequently used as a framework to investigate a variety of natural resource conservation issues (Dearden et al., 2006; Mangun, Throgmorton, Carver, \& Davenport, 2007; Oh \& Ditton, 2006). Specialization theory postulates that participants in an outdoor recreation activity (e.g., anglers, scuba divers, boaters) can be placed on a continuum ranging from general interest and low involvement at one end, to expert interest and high involvement in a leisure social world at the other end. Each level of specialization involves a change in distinctive behaviors, skills, and directions. These include equipment preference, type of experiences sought (goals), desired settings for the activity, attitudes toward resource management, preferred social context, and vacation patterns. The concept of recreation specialization is important because it allows researchers to analyze subgroups of populations, rather than aggregate the attitudes and preferences of novice, medium, and advanced participants into one larger group (C. Hawkins, Loomis, \& Salz, 2009; Salz, Loomis, \& Finn, 2001). Specialization theory includes eight propositions (Ditton et al., 1992): 
1. Persons participating in a given recreation activity are likely to become more specialized in that activity over time.

2. As level of specialization in a given recreation activity increases, the value of side bets will likely increase.

3. As level of specialization in a given recreation activity increases, the centrality of that activity in a person's life will likely increase.

4. As levels of specialization in a given recreation activity increase, acceptance and support for the rules, norms and procedures associated with the activity will likely increase.

5. As level of specialization in a given recreation activity increases, the importance attached to equipment and the skillful use of that equipment will likely increase.

6. As level of specialization in a given recreation activity increases, dependency on a specific resource will likely increase.

7. As level of specialization in a given recreation activity increases, level of mediated interaction relative to that activity will likely increase.

8. As level of specialization in a given recreation activity increases, the importance of activityspecific elements of the experience will decrease relative to non-activity-specific elements of the experience.

This study seeks to use both expectancy/discrepancy theory and recreational specialization to understand the broader concept of diver satisfaction. As a result, three research questions were developed and tested:

1. Do differences in discrepancy between expectations and experiences vary according to specialization level?

2. Do differences in satisfaction vary according to specialization level?

3. Will the resource attributes that are most important in explaining satisfaction vary according to specialization level?

\section{Methods}

\section{Sampling}

A sample of scuba divers in the Florida Keys was identified through in-person intercepts, designed to collect names and addresses for a subsequent mail survey. To ensure the representativeness of the sample, names and addresses of individuals were collected through intercepting people participating in a diving activity. Intercepts began in June 2006 and took place during approximately 1 week of each month during a 13-month period. Two main approaches were employed to collect a large enough overall sample: 1) on water intercepts, and 2) on land intercepts where respondents were selected at random at each location. On water intercepts targeted private boat owners or visitors who had rented a boat for the day, and scuba dive on or around coral reefs. This involved being on the water and communicating with divers in situ. On-land intercepts were performed at commercial dive shop operations, where divers could be contacted just before or after dives. The approach used in this study ensured that private boats coming from canal-side docks, rental boat, divers trailering boats, and individual divers from charter boats all had the potential to be included in the sample.

\section{Survey Development and Implementation}

The survey instrument was developed cooperatively with members of the Florida Reef Resilience Program working group, a process that yielded a 12-page instrument containing 171 variables. Questions were designed to cover a variety of social theories, but this study will focus on variables related to motivations, expectations, accomplishments, satisfaction, and recreation specialization. With the exception of recreation specialization, the variables selected have a conceptual basis in the literature (Driver, 1983) and were modified to fully represent the scenarios relevant to diving as a recreational activity. The recreation specialization items were modified from Salz et al. (2001) in the same way. Items on basic demographics, such as gender, age, race, ethnicity, income, and place of residence, that were included on the original survey instrument, were also examined for the purpose of this study.

\section{Discrepancy Level}

Discrepancy level was calculated as the difference between respondents' expectations and their actual experience on ten 5-point Likert scale resource attribute items. Respondents were first 
asked, "To what extent do you expect to be able to do each of the following on your most recent trip to a reef in the Florida Keys?" for each of the ten items. Then, they were asked later in the survey the "extent to which they were able to accomplish each of the following on their most recent trip to a reef in the Florida Keys?" The 10 items, conceptually derived from Driver (1983), were: a) seeing a healthy reef, b) experiencing easy diving conditions, c) experiencing good under water visibility, d) seeing undamaged reef sites, e) seeing marine life, f) seeing large fish, g) seeing unique underwater formations, h) seeing live coral, i) experiencing natural surroundings, and, j) relaxing. This discrepancy level provided context to the respondents' overall satisfaction level, with a negative score indicating expectations greater than achievement, and a positive score indicating achievement was greater than expectations.

\section{Satisfaction Index}

For each of the original 10 parent items listed above, respondents were also asked to indicate how satisfied they were with each on their most recent dive in the Florida Keys. Question response options were ordered from least satisfied (response option = 1) to most satisfied (response option $=5$ ) along a 5-point Likert scale. The results for all 10 items were summed and then used to generate the satisfaction index and locate users on a satisfaction continuum. The index was tested for reliability using Cronbach's coefficient alpha (Cronbach, 1951).

\section{Diver Specialization Index}

The diver specialization index used was based on an index developed and validated by Salz et al. (2001), which allowed the categorization of divers into meaningful subgroups based on the four social world characteristics of: orientation, experiences, relationships, and commitment (Ditton, et al., 1992; Unruh, 1979). The Salz et al. index utilized theory and an a priori method to generate the index items. For each characteristic, Unruh (1979) described four subworld types of participants: strangers, tourists, regulars, and insiders. Based on these descriptions, Salz and colleagues developed four survey questions that corresponded to Unruh's four characteristics. Each question contained four possible response options, with each option corresponding to one of the four recreation specialization levels (least, moderately, very, highly). Question response options consisted of statements describing a participant's connection to an activity relative to that particular characteristic and were ordered from least specialized (response option $=1$ ) to most specialized (response option $=4$ ). As designed, the least specialized participants would select option 1, and the most specialized participants would select option 4. The sum of the four responses (e.g., least specialized: $1+1+1+1=4$, highly specialized: $4+4+4+4=16$ ) was used to locate recreationists along the recreation specialization continuum. Salz et al. (2001) used item analysis to examine the internal consistency of their composite index. Bivariate comparisons of the four social world items and Cronbach's alpha supported inclusion of all four items in their recreation specialization index. The nature of the interitem predictability also supported the internal validity of the specialization index.

\section{Survey Implementation}

To maximize response rates, the survey materials were distributed using the Dillman Total Design Method (Dillman, 1978; Dillman, Smyth, \& Christian, 2009). Essentially this method involves personalization and repeat mailings. All outgoing envelopes were hand addressed in blue ink, and the cover letter was personalized to an individual person, and again hand signed in blue ink. Following an initial mailing having a normal postage stamp affixed (which includes the survey instrument, a cover letter, and a prepaid business return envelope to return the survey in), a postcard reminder/thank you was sent 1 week later to all persons who received the initial mailing. Three weeks after the initial mailing, a second mailing of materials was sent to all those who had not yet responded. The content of the second mailing was identical to the first, except for slight wording changes in the cover letter intended to encourage a response. Six weeks after the initial mailing, a third and final mailing was sent (again identical to the first) to those who had still not responded. 
Table 1

Mean Discrepancies Between Experience and Expectation on Resource Attributes According to Specialization Level

\begin{tabular}{|c|c|c|c|c|c|}
\hline \multirow[b]{2}{*}{ Resource Attribute Feature } & \multicolumn{3}{|c|}{ Specialization Level } & \multicolumn{2}{|c|}{ ANOVA } \\
\hline & Moderate & High & Very High & $F$ & Sig. \\
\hline Experiencing easy diving conditions & -0.06 & 0.04 & $\underline{0.39}$ & 8.724 & 0.000 \\
\hline Experiencing good underwater visibility & -0.27 & -0.27 & $\underline{0.06}$ & 5.997 & 0.003 \\
\hline Relaxing & $-\underline{0.06}$ & -0.11 & $\overline{0.04}$ & 1.833 & 0.161 \\
\hline Seeing unique underwater features & -0.03 & -0.09 & 0.04 & 0.777 & 0.460 \\
\hline Experiencing natural surroundings & $-\underline{0.09}$ & -0.04 & -0.01 & 0.384 & 0.681 \\
\hline Seeing large fish & $-\underline{0.13}$ & -0.20 & -0.12 & 0.377 & 0.686 \\
\hline Seeing live coral & $-\underline{0.14}$ & -0.19 & -0.14 & 0.245 & 0.782 \\
\hline Seeing a healthy reef & -0.16 & -0.20 & -0.22 & 0.145 & 0.865 \\
\hline Seeing undamaged reef sites & $-\overline{0.15}$ & -0.16 & -0.19 & 0.058 & 0.943 \\
\hline Seeing marine life & $\underline{0.09}$ & 0.11 & 0.11 & 0.051 & 0.950 \\
\hline
\end{tabular}

Means underscored by the same line are not significantly different $(p>0.05)$.

\section{Results}

Survey efforts resulted in a total of 1,595 returned and useable surveys from an initial sample of 2,867 , giving an overall response rate of $57.9 \%$. For the purposes of this study, only data from selfselected nonresident/tourist divers $(n=869)$ were included in the analysis since this was the population of interest.

Of all nonresident divers surveyed, 28\% were between 15 and 35 years of age, with the majority being over 40 (mean $=43.0$ years). The respondents were predominately male $(73 \%)$, and only $3 \%$ of the sample self-identified as Hispanic/ Spanish/Latino. Virtually all respondents (97.9\%) listed their race as white. Twenty-five percent of those surveyed reported their household income as $\$ 150,000$ or more, with $87 \%$ of respondents reporting a household income of greater than $\$ 45,000$.

The satisfaction index was created by first summing the satisfaction scores for all 10 items, with the sums ranging from a minimum of 10 to a maximum of 50. A three-level satisfaction index was then generated from this continuum with groups ranging from 10 to 26,27 to 31 , and 32 to 50 . The utilization of three levels, low, medium, and high satisfaction, provided groupings that were roughly equal in size ( $n=278,232$, and 330, respectively) and were large enough to guarantee sufficient statistical power for further analysis. The 10-item

Table 2

Mean Satisfaction Scores on Resource Attributes According to Specialization Level

\begin{tabular}{lllllll}
\hline & \multicolumn{2}{c}{ Specialization Level } & & \multicolumn{2}{c}{ ANOVA } \\
\cline { 2 - 5 } \cline { 5 - 6 } Resource Attribute Feature & Moderate & High & Very High & & $F$ & Sig. \\
\hline Relaxing & $\underline{3.82}$ & $\underline{4.19}$ & 4.40 & & 20.433 & 0.000 \\
Experiencing easy diving conditions & $\underline{3.49}$ & 3.59 & $\underline{3.90}$ & & 9.347 & 0.000 \\
Experiencing good underwater visibility & $\underline{3.47}$ & 3.40 & 3.60 & & 2.405 & 0.091 \\
Seeing undamaged reef sites & $\underline{3.42}$ & 3.42 & 3.28 & & 1.523 & 0.219 \\
Experiencing natural surroundings & $\underline{3.96}$ & 4.06 & 4.00 & & 0.819 & 0.441 \\
Seeing large fish & $\underline{3.40}$ & 3.31 & 3.32 & & 0.487 & 0.614 \\
Seeing marine life & $\underline{3.72}$ & 3.75 & 3.79 & & 0.329 & 0.720 \\
Seeing unique underwater features & $\underline{3.43}$ & 3.42 & 3.47 & & 0.173 & 0.841 \\
Seeing a healthy reef & $\underline{3.48}$ & 3.50 & 3.45 & & 0.155 & 0.856 \\
Seeing live coral & $\underline{3.58}$ & 3.62 & 3.59 & & 0.113 & 0.893 \\
\hline
\end{tabular}

Means underscored by the same line are not significantly different $(p>0.05)$. 
Table 3

Stepwise Regression Model for Full Sample of Nonresident Divers

\begin{tabular}{lcccc}
\hline Model & $R$ & $R^{2}$ & $\begin{array}{c}\text { Adjusted } \\
R^{2}\end{array}$ & $\begin{array}{c}\text { SE of the } \\
\text { Estimate }\end{array}$ \\
\hline One $^{\mathrm{a}}$ & 0.401 & 0.161 & 0.160 & 0.76040 \\
Two $^{\mathrm{b}}$ & 0.483 & 0.233 & 0.231 & 0.72723 \\
Three $^{\mathrm{c}}$ & 0.513 & 0.263 & 0.260 & 0.71334 \\
Four $^{\mathrm{d}}$ & 0.521 & 0.272 & 0.268 & 0.70959 \\
Five $^{\mathrm{e}}$ & 0.528 & 0.278 & 0.274 & 0.70682 \\
\hline
\end{tabular}

aPredictors: (Constant), seeing large fish.

bPredictors: (Constant), seeing large fish, experiencing good underwater visibility.

'Predictors: (Constant), seeing large fish, experiencing good underwater visibility, seeing a healthy reef.

dPredictors: (Constant), seeing large fish, experiencing good underwater visibility, seeing a healthy reef, experiencing easy diving conditions.

'Predictors: (Constant), seeing large fish, experiencing good underwater visibility, seeing a healthy reef, experiencing easy diving conditions, seeing undamaged reef sites. index was then tested for index item reliability $(\alpha=$ 0.921). However, based upon interitem correlation results, the index was modified to include only eight items in order to eliminate the high correlations present in the original 10 parent index $(\alpha=$ 0.891). The items that were excluded were "seeing a healthy reef" and "seeing live coral."

Initially, respondents were categorized into four levels of specialization, mirroring the method used by Salz et al. (2001). However, the sample size of nonresident divers in the least specialized category was considered to be too small for the purposes of statistical analysis. The small sample size in this category could potentially be attributed to the nature of scuba diving itself. Scuba divers are required to pass a comprehensive level of basic training before the activity can commence, which vastly reduced the number of people classified into the least specialized group. Therefore, respondents in the least and moderate categories were combined to yield three final specialization groups of "moderate" (specialization level 2 with an $n$ of 248), "high"

Table 4

Stepwise Regression Coefficients for Full Sample of Nonresident Divers

\begin{tabular}{|c|c|c|c|c|c|}
\hline \multirow[b]{2}{*}{ Model } & \multicolumn{2}{|c|}{$\begin{array}{l}\text { Unstandardized } \\
\text { Coefficients }\end{array}$} & \multicolumn{2}{|c|}{$\begin{array}{l}\text { Standardized } \\
\text { Coefficients }\end{array}$} & \multirow[b]{2}{*}{ Sig. } \\
\hline & $\mathrm{B}$ & $\mathrm{SE}$ & $\mathrm{B}$ & $t$ & \\
\hline \multicolumn{6}{|l|}{ One } \\
\hline (Constant) & 2.153 & 0.027 & & 79.935 & 0.000 \\
\hline Seeing large fish & 0.240 & 0.019 & 0.401 & 12.402 & 0.000 \\
\hline \multicolumn{6}{|l|}{ Two } \\
\hline (Constant) & 2.177 & 0.026 & & 84.034 & 0.000 \\
\hline Seeing large fish & 0.178 & 0.020 & 0.297 & 8.952 & 0.000 \\
\hline Experiencing good underwater visibility & 0.199 & 0.023 & 0.289 & 8.719 & 0.000 \\
\hline \multicolumn{6}{|l|}{ Three } \\
\hline (Constant) & 2.192 & 0.026 & & 85.799 & 0.000 \\
\hline Seeing large fish & 0.143 & 0.020 & 0.240 & 7.049 & 0.000 \\
\hline Experiencing good underwater visibility & 0.159 & 0.023 & 0.231 & 6.773 & 0.000 \\
\hline Seeing a healthy reef & 0.144 & 0.025 & 0.197 & 5.706 & 0.000 \\
\hline \multicolumn{6}{|l|}{ Four } \\
\hline (Constant) & 2.174 & 0.026 & & 83.239 & 0.000 \\
\hline Seeing large fish & 0.137 & 0.020 & 0.230 & 6.758 & 0.000 \\
\hline Experiencing good underwater visibility & 0.112 & 0.028 & 0.163 & 4.017 & 0.000 \\
\hline Seeing a healthy reef & 0.138 & 0.025 & 0.190 & 5.502 & 0.000 \\
\hline Experiencing easy diving conditions & 0.077 & 0.025 & 0.120 & 3.083 & 0.002 \\
\hline \multicolumn{6}{|l|}{ Five } \\
\hline (Constant) & 2.173 & 0.026 & & 83.544 & 0.000 \\
\hline Seeing large fish & 0.131 & 0.020 & 0.219 & 6.433 & 0.000 \\
\hline Experiencing good underwater visibility & 0.096 & 0.028 & 0.139 & 3.381 & 0.001 \\
\hline Seeing a healthy reef & 0.101 & 0.029 & 0.138 & 3.504 & 0.000 \\
\hline Experiencing easy diving conditions & 0.080 & 0.025 & 0.125 & 3.214 & 0.001 \\
\hline Seeing undamaged reef sites & 0.072 & 0.026 & 0.106 & 2.701 & 0.007 \\
\hline
\end{tabular}


Table 5

Stepwise Regression Model for Nonresident Divers in the Moderate Specialization Group

\begin{tabular}{lcccc}
\hline Model & $R$ & $R^{2}$ & $\begin{array}{c}\text { Adjusted } \\
R^{2}\end{array}$ & $\begin{array}{c}\text { SE of the } \\
\text { Estimate }\end{array}$ \\
\hline One $^{\mathrm{a}}$ & 0.467 & 0.218 & 0.214 & 0.74003 \\
Two $^{\mathrm{b}}$ & 0.563 & 0.317 & 0.312 & 0.69278 \\
Three $^{\mathrm{c}}$ & 0.603 & 0.364 & 0.356 & 0.67009 \\
Four $^{\mathrm{d}}$ & 0.616 & 0.380 & 0.369 & 0.66319 \\
\hline
\end{tabular}

aPredictors: (Constant), seeing live coral.

'Predictors: (Constant), seeing live coral, experiencing easy diving conditions.

'Predictors: (Constant), seeing live coral, experiencing easy diving conditions, seeing large fish.

dPredictors: (Constant), seeing live coral, experiencing easy diving conditions, seeing large fish, experiencing natural surroundings.

(specialization level 3 with an $n$ of 371), and "very high" (specialization level 4 with an $n$ of 238). The specialization index was also tested for index item reliability ( $\alpha=0.824)$.

In order to investigate the first research question (Do differences in discrepancy between expectations and experiences vary according to specialization level?), discrepancy means (the difference between expectations and actual experience) for the
10 resource attributes were calculated (Table 1). A one-way analysis of variance was used to test for differences between these levels, and the results showed significant differences for just two of the 10 -parent items $(p<0.05)$, "experiencing easy diving conditions" and "experiencing good underwater visibility" (Table 5). On both these items, the very highly specialized group was significantly higher than the other specialization levels.

To examine the second research question (Do differences in satisfaction vary according to specialization level?), differences between mean scores for the 10 satisfaction items were examined. Satisfaction means associated with each parent item were generated for each specialization level (Table 2). A one-way analysis of variance was then used to test for differences between these means according to specialization level. Significant differences were found for the items "relaxing" and "experiencing easy diving conditions."

To address the third research question (Will the resource attributes that are most important in explaining satisfaction vary according to specialization level?), a stepwise regression was conducted using both the satisfaction index and the discrepancy scores. A stepwise regression generates

Table 6

Stepwise Regression Coefficients for Nonresident Divers in the Moderate Specialization Group

\begin{tabular}{|c|c|c|c|c|c|}
\hline \multirow[b]{2}{*}{ Model } & \multicolumn{2}{|c|}{$\begin{array}{l}\text { Unstandardized } \\
\text { Coefficients }\end{array}$} & \multicolumn{2}{|c|}{$\begin{array}{l}\text { Standardized } \\
\text { Coefficients }\end{array}$} & \multirow[b]{2}{*}{ Sig. } \\
\hline & B & SE & B & $t$ & \\
\hline \multicolumn{6}{|l|}{ One } \\
\hline (Constant) & 2.069 & 0.049 & & 42.510 & .000 \\
\hline Seeing live coral & 0.353 & 0.044 & 0.467 & 8.020 & 0.000 \\
\hline \multicolumn{6}{|l|}{ Two } \\
\hline (Constant) & 2.079 & 0.046 & & 45.596 & 0.000 \\
\hline Seeing live coral & 0.267 & 0.044 & 0.353 & 6.091 & 0.000 \\
\hline Experiencing easy diving conditions & 0.215 & 0.037 & 0.336 & 5.795 & 0.000 \\
\hline \multicolumn{6}{|l|}{ Three } \\
\hline (Constant) & 2.087 & 0.044 & & 47.277 & 0.000 \\
\hline Seeing live coral & 0.197 & 0.046 & 0.261 & 4.328 & 0.000 \\
\hline Experiencing easy diving conditions & 0.185 & 0.037 & 0.288 & 5.035 & 0.000 \\
\hline Seeing large fish & 0.137 & 0.033 & 0.246 & 4.104 & 0.000 \\
\hline \multicolumn{6}{|l|}{ Four } \\
\hline (Constant) & 2.088 & 0.044 & & 47.780 & 0.000 \\
\hline Seeing live coral & 0.144 & 0.050 & 0.190 & 2.858 & 0.005 \\
\hline Experiencing easy diving conditions & 0.173 & 0.037 & 0.270 & 4.727 & 0.000 \\
\hline Seeing large fish & 0.127 & 0.033 & 0.228 & 3.811 & 0.000 \\
\hline Experiencing natural surroundings & 0.145 & 0.060 & 0.154 & 2.405 & 0.017 \\
\hline
\end{tabular}


Table 7

Stepwise Regression Model for Nonresident Divers in the High Specialization Group

\begin{tabular}{lcccc}
\hline Model & $R$ & $R^{2}$ & $\begin{array}{c}\text { Adjusted } \\
R^{2}\end{array}$ & $\begin{array}{c}\text { SE of the } \\
\text { Estimate }\end{array}$ \\
\hline One $^{\mathrm{a}}$ & 0.473 & 0.224 & 0.221 & 0.71986 \\
Two $^{\mathrm{b}}$ & 0.543 & 0.295 & 0.291 & 0.68703 \\
Three $^{\mathrm{c}}$ & 0.574 & 0.329 & 0.323 & 0.67123 \\
\hline
\end{tabular}

aPredictors: (Constant), experiencing good underwater visibility.

bPredictors: (Constant), experiencing good underwater visibility, seeing a healthy reef.

'Predictors: (Constant), experiencing good underwater visibility, seeing a healthy reef, seeing large fish.

a series of regression models in which the order of predictive variables (discrepancy scores) is based upon the amount of variance in the satisfaction index that is explained. New variables are continually loaded into the model until no significant contribution to variance explanation occurs. The overall regression model for all nonresident divers used 5 of the 10 parent items to explain over $27 \%$ of the variance $\left(r^{2}=0.278\right)$ (Table 3, Table 4).

Step-wise regression models were then generated for each specialization level in order to provide a greater level of detail regarding which items were specifically important to explaining satisfaction for each specialization level. Only one item, "seeing large fish," registered as a contributor to satisfaction across all specialization levels, suggesting that this feature contributed significantly to overall diver satisfaction. However, the primary predictor for each specialization level was different.

For the moderate specialization level "seeing live coral" was the primary factor $\left(r^{2}=0.218\right)$ in a four-item model $\left(r^{2}=0.380\right)$ (Table 5, Table 6). The variance associated with the high specialization level model was explained in a three-item model $\left(r^{2}=0.329\right)$ with "experiencing good visibility" registering as the greatest contributor $\left(r^{2}=\right.$ 0.224) (Table 7, Table 8). Finally, the highest specialization level also generated a three-item model $\left(r^{2}=0.159\right)$ with "seeing a healthy reef" explaining the majority of the variance $\left(r^{2}=0.106\right)$ (Table 9, Table 10).

\section{Discussion}

Discrepancy scores shown in Table 1 varied from -0.27 to 0.39 . Of the individual discrepancies measured (10 items per specialization level), only eight were positive. This suggests that, in general, nonresident divers tended to expect slightly more than they achieved on their most recent dive. Only 2 of the 10 discrepancies were significant according to specialization level ("experiencing easy diving conditions" and "experiencing good underwater visibility"). However, no large discrepancies were recorded across specialization level for any of the items, which suggests that most divers have realistic

Table 8

Stepwise Regression Coefficients for Nonresident Divers in the High Specialization Group

\begin{tabular}{|c|c|c|c|c|c|}
\hline \multirow[b]{2}{*}{ Model } & \multicolumn{2}{|c|}{$\begin{array}{l}\text { Unstandardized } \\
\text { Coefficients }\end{array}$} & \multicolumn{2}{|c|}{$\begin{array}{l}\text { Standardized } \\
\text { Coefficients }\end{array}$} & \multirow[b]{2}{*}{ Sig. } \\
\hline & $\mathrm{B}$ & $\mathrm{SE}$ & $\mathrm{B}$ & $t$ & \\
\hline \multicolumn{6}{|l|}{ One } \\
\hline (Constant) & 2.212 & 0.040 & & 55.205 & 0.000 \\
\hline Experiencing good underwater visibility & 0.331 & 0.034 & 0.473 & 9.813 & 0.000 \\
\hline \multicolumn{6}{|l|}{ Two } \\
\hline (Constant) & 2.230 & 0.038 & & 58.125 & 0.000 \\
\hline Experiencing good & 0.234 & 0.036 & 0.334 & 6.450 & 0.000 \\
\hline Seeing a healthy reef & 0.220 & 0.038 & 0.301 & 5.804 & 0.000 \\
\hline \multicolumn{6}{|l|}{ Three } \\
\hline (Constant) & 2.236 & 0.038 & & 59.600 & 0.000 \\
\hline Experiencing good underwater visibility & 0.189 & 0.037 & 0.270 & 5.096 & 0.000 \\
\hline Seeing a healthy reef & 0.179 & 0.038 & 0.244 & 4.658 & 0.000 \\
\hline Seeing large fish & 0.133 & 0.032 & 0.211 & 4.105 & 0.000 \\
\hline
\end{tabular}


Table 9

Stepwise Regression Model for Nonresident Divers in the Very High Specialization Group

\begin{tabular}{lcccc}
\hline Model & $R$ & $R^{2}$ & $\begin{array}{c}\text { Adjusted } \\
R^{2}\end{array}$ & $\begin{array}{c}\text { SE of the } \\
\text { Estimate }\end{array}$ \\
\hline One $^{\mathrm{a}}$ & 0.325 & 0.106 & 0.101 & 0.79491 \\
Two $^{\mathrm{b}}$ & 0.380 & 0.144 & 0.136 & 0.77929 \\
Three $^{\mathrm{c}}$ & 0.399 & 0.159 & 0.148 & 0.77422 \\
\hline
\end{tabular}

aPredictors: (Constant), seeing a healthy reef.

'Predictors: (Constant), seeing a healthy reef, seeing large fish. 'Predictors: (Constant), seeing a healthy reef, seeing large fish, seeing undamaged reef sites.

expectations when it comes to diving in the Florida Keys. Due to the fact that the size of the discrepancies is relatively small, and only two discrepancies were statistically significant according to specialization level, it would be expected that few differences on measures of satisfaction would be found (Table 2). Overall, it appears that nonresident divers are satisfied with their diving experience in the Florida Keys, with all measures being moderately satisfied or above (mean $=3)$.

The comparison of item-specific satisfaction according to specialization level revealed only two significant differences, "experiencing easy diving conditions" and "relaxing." Interestingly, these two items are concerned with the actual process or experience of diving as opposed to specific natural biophysical features that may be encountered on a dive. The item "experiencing good underwater visibility" approached statistical significance ( $p=$ 0.091). The above results are of interest, in that these three significant or near significant variables (out of 10) are the same for both the discrepancy and satisfaction indicators. On the discrepancy scores, more positive scores were observed for more specialized divers, suggesting that these same divers would report higher levels of satisfaction on these same items. The satisfaction scores on these items confirm this, which is consistent with existing literature (del Bosque \& Martin, 2008).

The above analysis suggests that across the items tested, nonresident divers in this study are relatively homogeneous in terms of their expectations, experiences, and satisfaction levels. In effect, there seems to be little difference in what they expected from the resource or experience, and what they achieved, or their satisfaction. This finding supports other studies in different geographical locations (Uyarra, Watkinson, \& Cote, 2009) and reinforced the concept of a homogenous element within the dive population visiting the Florida Keys.

However, the stepwise regression analysis suggests that different items contributed to the satisfaction levels recorded (Tables 5-10). The regression analysis supports the argument that Todd et al. (2002) advanced suggesting that individuals participating in a particular activity may seek different

Table 10

Stepwise Regression Coefficients for Nonresident Divers in the Very High

Specialization Group

\begin{tabular}{|c|c|c|c|c|c|}
\hline \multirow[b]{2}{*}{ Model } & \multicolumn{2}{|c|}{$\begin{array}{c}\text { Unstandardized } \\
\text { Coefficients }\end{array}$} & \multicolumn{2}{|c|}{$\begin{array}{l}\text { Standardized } \\
\text { Coefficients }\end{array}$} & \multirow[b]{2}{*}{ Sig. } \\
\hline & $\mathrm{B}$ & SE & B & $t$ & \\
\hline \multicolumn{6}{|l|}{ One } \\
\hline (Constant) & 2.234 & 0.054 & & 41.411 & 0.000 \\
\hline Seeing a healthy reef & 0.259 & 0.050 & 0.325 & 5.129 & 0.000 \\
\hline \multicolumn{6}{|l|}{ Two } \\
\hline (Constant) & 2.236 & 0.053 & & 42.280 & 0.000 \\
\hline Seeing a healthy reef & 0.201 & 0.053 & 0.252 & 3.810 & 0.000 \\
\hline Seeing large fish & 0.125 & 0.039 & 0.210 & 3.166 & 0.002 \\
\hline \multicolumn{6}{|l|}{ Three } \\
\hline (Constant) & 2.244 & 0.053 & & 42.591 & 0.000 \\
\hline Seeing a healthy reef & 0.164 & 0.056 & 0.205 & 2.934 & 0.004 \\
\hline Seeing large fish & 0.117 & 0.039 & 0.196 & 2.972 & 0.003 \\
\hline Seeing undamaged reef sites & 0.091 & 0.046 & 0.133 & 1.980 & 0.049 \\
\hline
\end{tabular}


outcomes and specific attributes that vary according to expectations (Asafu-Adjaye \& Tapsuwan, 2008). For all specialization levels, the models generated explained a reasonable amount of the total variance, which suggests that diver satisfaction is related both to discrepancies between expectations and experience, and to specialization level. One item, "seeing large fish," was included in all the regression models generated irrespective of specialization level.

It may also follow that if satisfaction can be linked to such a specific resource, then dive experiences that focus on fish as a natural feature would contribute to satisfactory recreational experiences for divers of all specialization levels. This may be of particular interest to resource managers since the argument could potentially be made that fragile or pristine environments could be protected more easily without detracting from the recreational experience. For example, less specialized divers, who may have more difficulties in controlling buoyancy and so could potentially damage reefs, could have experiences provided for them away from key locations as long as the opportunity to view large fish remained.

The inventory of resource attributes, specifically in the case of coral reefs, cannot be stored or adjusted to changes in demand. As coral reefs form over hundreds of years, they can primarily be described as a static fixed reserve, one which varies slightly with regard to quality and associated features such as algal cover, fish abundance, or visibility (Pendleton \& Rooke, 2006). This puts pressure on resource managers and tourism planners to effectively plan how to market and manage these discreet goods. In other words, determining where the balance between offering satisfying diving experiences and long term management of the resource can be struck (Tratalos \& Austin, 2001). Understanding of the preferences and needs of different subgroups of divers can generate the opportunity to maximize benefits to both the tourist and the existing resources (Pendleton, 1994). However, failure to utilize the full range of existing measures to understand the population of interest can lead to the exclusion of important underlying variances. These variances provide more accurate information on which to assess and plan marketing and management strategies.

\section{Conclusion}

Segmenting the nonresident diving population visiting the Florida Keys according to specialization level allowed a theoretical basis to underpin recommendations for both resource managers and the dive industry. The article demonstrated that nonresident recreational scuba divers in the Florida Keys could be successfully subdivided into different subgroups by specialization level, based on two measures of satisfaction. The "bundle" of resource attributes that contribute to a scuba divers satisfaction level is made up of different features for each diver specialization level. Just using satisfaction means, or just looking at discrepancy scores belies the complex differences between specialization groups, which only becomes apparent when compared with results from the regression model. Each subgroup had a different primary factor contributing to overall level of satisfaction. This study provided a conceptually grounded understanding of those group differences that could be usefully applied in a variety of management and tourism related contexts. Understanding the characteristics of current visitors can provide critical insight into how to maintain and potentially grow the current dive market share in the Florida Keys.

Although statistically significant differences were found between divers of the three specialization levels identified during this study, these differences are less functional in utilitarian terms for managers and the tourism market. This issue may be addressed by expanding the initial item pool to include a greater range of Driver (1983) motivations, including both resource attributes and nonactivity-specific items that are common to a range of recreational activities, such as "spending time with family." This would allow proposition 8 of specialization theory to be more fully explored as a function of satisfaction. Gathering primary data on elements that specifically contributed to diver expectations may also assist with a broader understanding of the interplay between the three social science theories utilized during this study.

\section{Biographical Notes}

Shona Paterson is a Ph.D. student in the Coastal Resources Management Program at East Carolina University and holds a Masters in Tropical Coastal Management. Her research interests include sustainable tourism and coastal resilience. 
Sarah Young is a Ph.D. student in the Coastal Resources Management Program at East Carolina University and holds a Masters in Tropical Coastal Management. Her research interests include marine policy and fisheries.

David K. Loomis is an associate professor at East Carolina University and holds a split appointment between the Institute for Coastal Science and Policy and the Department of Recreation and Leisure Studies. He holds a Ph.D. from Texas A\&M University.

William Obenour is an associate professor in the Center for Sustainable Tourism, Department of Recreation and Leisure Studies at East Carolina University. His research interests include travel decision making for nature and cultural tourists, destination development in symbolic capital, and backpacker tourism.

\section{References}

Alegre, J., \& Garau, J. (2010). Tourism satisfaction and dissatisfaction. Annals of Tourism Research, 37(1), 52-73.

Alexandris, K., Kouthouris, C., \& Meligdis, A. (2006). Increasing customers' loyalty in a skiing resort: The contribution of place attachment and service quality. International Journal of Contemporary Hospitality Management, 18(5), 414-425.

Asafu-Adjaye, J., \& Tapsuwan, S. (2008). A contingent valuation study of scuba diving benefits: Case study in $\mathrm{Mu}$ Ko Similan Marine National Park, Thailand. Tourism Management, 29(6), 1122-1130.

Baker, D., \& Crompton, J. (2000). Quality, satisfaction and behavioral intentions. Annals of Tourism Research, 27(3), 785-804.

Barker, N. H. L., \& Roberts, C. M. (2004). SCUBA diver behaviour and the management of diving impacts on coral reefs. Biological Conservation, 120(4), 481-489.

Beard, J. G., \& Ragheb, M. G. (1980). Measuring leisure satisfaction. Journal of Leisure Research, 12(1), 20-33.

Bigne, E., Sanchez, M., \& Sanchez, J. (2001). Tourism image, evaluation variables and after pruchase behaviour: Inter-relationship. Tourism Management, 22, 607616.

Bowen, D., \& Clarke, J. (2009). Contemporary tourist behaviour: Yourself and others as tourists. Cambridge, MA: CABI.

Bryan, H. (1977). Leisure value systems and recreational specialization: The case of trout fishermen. Journal of Leisure Research, 9, 174-187.

Buckley, R. (2010). Adventure tourism management. Amsterdam: Elsevier.

Burns, R. C., Graefe, A. R., \& Absher, J. D. (2003). Alternate measurement approaches to recreational customer satisfaction: Satisfaction-only versus gap scores. Leisure Sciences, 25(4), 363.

Campo-Martínez, S., Garau-Vadell, J. B., \& Martínez-Ruiz,
M. P. (2010). Factors influencing repeat visits to a destination: The influence of group composition. Tourism Management, 31(6), 862-870.

Chipman, B. D., \& Helfrich, L. A. (1988). Recreational specializations and motivations of Virginia river anglers. North American Journal of Fisheries Management, 8, 390-398.

Crompton, J. (1979). Motivation for pleasure vacations. Annals of Tourism Research, 6, 408-424.

Cronbach, L. J. (1951). Coefficient alpha and the internal structure of tests. Psychometrika, 16, 297-334.

Cutler, S. Q., \& Carmichael, B. A. (2010). The dimensions of the tourist experience. In M. Morgan, P. Lugosi, \& J. R. B. Ritchie (Eds.), The tourism and leisure experience (pp. 3-27). Bristol, UK: Channel View Publications.

Davis, D., \& Tisdell, C. (1995). Recreational scuba-diving and carrying-capacity in marine protected areas. Ocean \& Coastal Management, 26(1), 19-40.

Dearden, P., Bennett, M., \& Rollins, R. (2006). Implications for coral reef conservation of diver specialization. Environmental Conservation, 33(4), 353-363.

Dearden, P., Bennett, M., \& Rollins, R. (2007). Perceptions of diving impacts and implications for reef conservation. Coastal Management, 35(2-3), 305-317.

del Bosque, I. R., \& Martin, H. S. (2008). Tourist satisfaction a cognitive-affective model. Annals of Tourism Research, 35(2), 551-573.

Di Franco, A., Marchini, A., Baiata, P., Milazzo, M., \& Chemello, R. (2009). Developing a SCUBA trail vulnerability index (STVI): A case study from a Mediterranean MPA. Biodiversity and Conservation, 18(5), 12011217.

Dillman, D. (1978). Mail and telephone surveys: The total design method. New York: John Wiley \& Sons, Inc.

Dillman, D., Smyth, J., \& Christian, L. (2009). Internet, mail, and mixed-mode surveys: The tailored design method. Hoboken, NJ: John Wiley \& Sons.

Dimmock, K. (2009). Finding comfort in adventure: Experiences of recreational SCUBA divers. Leisure Studies, 28(3), 279-295.

Ditton, R. B., Loomis, D. K., \& Choi, S. (1992). Recreation specialization: Re-conceptualization from a social worlds perspective. Journal of Leisure Research, 24(1), 33.

Driver, B. (1983). Master list of items for recreation experience preference scales and domains. Unpublished document. . USDA Forest Service, Fort Collins, CO: Rocky Mountain Forest and Range Experiment Station.

Fitzsimmons, C. (2008). Why dive? and Why here?: A study of recreational diver enjoyment at a Fijian eco-tourist resort. Tourism in Marine Environments, 5(2-3), 159173.

Hasler, H., \& Ott, J. A. (2008). Diving down the reefs? Intensive diving tourism threatens the reefs of the northern Red Sea. Marine Pollution Bulletin, 56(10), 1788-1794.

Hawkins, C., Loomis, D. K., \& Salz, R. (2009). A replication of the internal validity and reliability of a 
multivariable index to measure recreation specialization. Human Dimensions of Wildlife, 14(4), 293-300.

Hawkins, J. P., \& Roberts, C. M. (1993). Effects of recreational scuba diving on coral reefs: Trampling on reef-flat communities. Journal of Applied Ecology, 30(1), 25-30.

Hawkins, J. P., Roberts, C. M., Van't Hof, T., de Meyer, K., Tratalos, J., \& Aldam, C. (1999). Effects of recreational SCUBA diving on Caribbean coral and fish communities. Conservation Biology, 13(4), 888-897.

Jennings, G. (2003). Marine tourism. In S. Hudson (Ed.), Sport and adventure tourism (pp. 125-164). Binghamton, NY: Haworth Hospitality Press.

Joppe, M., Martin, D., \& Waalen, J. (2001). Toronto's image as a destination: A comparative importance-satisfaction analysis by origin of visitor. Journal of Travel Research, $39,252-260$.

Kozak, M. (2001). Repeaters' behavior at two distinct destinations. Annals of Tourism Research, 28, 784-807.

Lawler, E. (1973). Motivations in work organizations. Monterey, CA: Brooks/Cole.

Lee, C., Lee, Y., \& Lee, B. (2005). Korea's destination image formed by the 2002 World Cup. Annals of Tourism Research, 32, 839-858.

Lee, J., Graefe, A. R., \& Burns, R. C. (2004). Service quality, satisfaction, and behavioral intention among forest visitors. Journal of Travel \& Tourism Marketing, 17(1), 73-82.

Leeworthy, V. R., \& Ehler, R. (2010). Linking the economy and environment of the Florida Keys/Key West, importance and satisfaction ratings by recreating visitors to the Florida Keys/Key West 2007-08. Silver Spring, MD: National Oceanic and Atmospheric Administration.

Leeworthy, V. R., Loomis, D. K., \& Paterson, S. K. (2010). Visitor profiles: Florida Keys/Key West 2007-08. Silver Spring, MD: National Oceanic and Atmospheric Administration.

Leeworthy, V. R., \& Wiley, P. (2001). Current participation patterns in marine recreation. Silver Spring, M: US Department of Commerce. National Oceanic and Atmospheric Administration. National Ocean Service. Special Projects.

Leiper, N. (1990). Tourism systems: An interdisciplinary approach. Palmerson North, New Zealand: Massey University.

MacCarthy, M., O’Neill, M., \& Williams, P. (2006). Customer satisfaction and scuba-diving: Some insights from the deep. The Service Industries Journal, 26(5), 537-555.

Mangun, J. C., Throgmorton, K. W., Carver, A. D., \& Davenport, M. A. (2007). Assessing stakeholder perceptions: Listening to avid hunters of western Kentucky. Human Dimensions of Wildlife, 12, 157-168.

Mannell, R. C., \& Iso-Ahola, S. E. (1987). Psychological nature of the leisure and tourism experience. Annals of Tourism Research, 14(3), 314-329.

Manning, R. E. (1999). Studies in outdoor recreation: Search and research for satisfaction. Corvallis, OR: Oregon State University Press.
Moscardo, G. (1999). Making visitors mindful: Principles for creating sustainable visitor experiences through effective communication. Champaign, IL: Sagamore Publishing.

Musa, G. (2002). Sipadan: A scuba-diving paradise: An analysis of tourism impact, diver satisfaction and tourism management. Tourism Geographies, 4(2), 195-209.

Musa, G., Kadir, S. L. S. A., \& Lee, L. (2006). Layang Layang: An empirical study on scuba divers' satisfaction. Tourism in Marine Environments, 2(2), 89-102.

Oh, C.O., \& Ditton, R. B. (2006). Using recreation specialization to understand multi-attribute management preferences. Leisure Sciences, 28(4), 369-384.

Oppermann, M. (2000). Tourism destination loyalty. Journal of Travel Research, 39(1), 78-84.

Pendleton, L. (1994). Environmental quality and recreation demand in a Caribbean coral reef. Coastal Management, 22,399-404.

Pendleton, L., \& Rooke, J. (2006). Understanding the potential economic value of scuba diving and snorkeling: California. Retrieved 01/24/2011 from www.linkbc.cal torc/downs 1/UnderstandingDiveImpacts.pdf

Pizam, A., \& Milman, A. (1993). Predicting satisfaction among first time visitors to a destination by using the expectancy disconfirmation theory. International Journal of Hospitality Management, 12(2), 197-209.

Pizam, A., Neumann, Y., \& Reichel, A. (1978). Dimensions of tourist satisfaction with a destination area. Annals of Tourism Research, 5(3), 314-322.

Porter, L. W., \& Lawler, E. E. (1968). Managerial attitudes and performance. Homewood, IL: Irwin.

Ragheb, M. G. (1980). Interrelationships among leisure participation, leisure satisfaction, and leisure attitudes. Journal of Leisure Research, 12(2), 138-149.

Rouphael, A. B., \& Inglis, G. J. (1997). Impacts of recreational SCUBA diving at sites with different reef topographies. Biological Conservation, 82(3), 329-336.

Rudd, M., \& Tupper, M. (2002). The impact of Nassau grouper size and abundance on scuba diver site selection and MPA economics. Coastal Management, 30, 133-151.

Ryan, C. (2002). From motivation to assessment. In C. Ryan (Ed.), The tourist experience. New York: Continuum.

Salz, R. J., Loomis, D. K., \& Finn, K. L. (2001). Development and validation of a specialization index and testing of specialization theory. Human Dimensions of Wildlife, 6(4), 239-258.

Shafer, E. L. (1969). The average camper who doesn't exist (Res. Pap. NE-142). Upper Darby, PA: U.S. Department of Agriculture, Forest Service, Northeastern Forest Experiment Station.

Sorice, M. G., Oh, C.-O., \& Ditton, R. B. (2007). Managing scuba divers to meet ecological goals for coral reef conservation. AMBIO: A Journal of the Human Environment, 36(4), 316-322.

Tapsuwan, S., \& Asafu-Adjaye, J. (2008). Estimating the economic benefit of scuba diving in the Similan Islands, Thailand. Coastal Management, 36(5), 431-442.

Thur, S. M. (2010). User fees as sustainable financing 
mechanisms for marine protected areas: An application to the Bonaire National Marine Park. Marine Policy, 34(1), 63-69.

Todd, S., Graefe, A., \& Mann, W. (2002). Differences in scuba diver motivations based on level of development. Paper presented at the Proceedings of the 2001 Northeastern Recreation Symposium, Lake George, NY.

Tratalos, J. A., \& Austin, T. J. (2001). Impacts of recreational scuba diving on coral communities of the Caribbean island of Grand Cayman. Biological Conservation, 102(1), 67-75.

Unruh, D. R. (1979). Characteristics and types of participation in social worlds. Symbolic Interaction, 2, 115-127.
Uyarra, M., Watkinson, A., \& Cote, I. M. (2009). Managing dive tourism for the sustainable use of coral reefs: Validating diver perceptions of attractive site features. Environmental Management, 43(1), 1-16.

Vroom, V. H. (1964). Work and movitation. New York: John Wiley \& Sons, Inc..

Wielgus, J., Balmford, A., Lewis, T. B., Mora, C., \& Gerber, L. R. (2010). Coral reef quality and recreation fees in marine protected areas. Conservation Letters, 3(1), $38-44$.

Yoon, Y., \& Uysal, M. (2005). An examination of the effects of motivation and satisfaction on destination loyalty: A structural model. Tourism Management, 26(1), 45-56. 